\title{
Characterizing nanoscale changes in the activity of VEGFR-2 on glioma microvascular endothelial cell membranes using atomic force microscopy
}

\author{
DEXIANG ZHOU, SHENGQUAN ZHAN, DONG ZHOU, PENG WANG, \\ GUANGZHONG CHEN, KUN QIN and XIAOFENG LIN \\ Department of Neurosurgery, Guangdong General Hospital, \\ Guangdong Academy of Medical Sciences, Guangzhou, Guangdong 510080, P.R. China
}

Received September 30, 2015; Accepted November 4, 2016

DOI: $10.3892 /$ etm.2016.4014

\begin{abstract}
The aim of the current study was to demonstrate the distribution of VEGFR-2 on glioma microvascular endothelial cells on a nanoscale and investigate changes in VEGFR-2 activity following treatment with the VEGFR-2 inhibitor and agonist sorafenib and bradykinin, respectively. Three groups were evaluated in this study: Control glioma microvascular endothelial cells, sorafenib-treated glioma microvascular endothelial cells and bradykinin-treated glioma microvascular endothelial cells. Changes in the activity of VEGFR-2 on the glioma microvascular endothelial cell membranes following treatment with sorafenib and bradykinin were characterized by atomic force microscopy (AFM). Colloidal gold-labeled immune complexes and AFM were used to visualize the distribution of VEGFR-2 on the cell membranes. In the control group, VEGFR-2, which was observed as numerous globular structures, was evenly distributed on the cell surface membranes. The majority of the receptors were active. In the sorafenib group, only a few globular structures were observed on the cell membranes, with a density significantly lower than that in the control group $(\mathrm{P}<0.01)$. Furthermore, compared with the control group, fewer of the receptors were active. In the bradykinin group, numerous globular structures were densely distributed on the cell membranes, with a density significantly higher than that in the control group $(\mathrm{P}<0.01)$. The distribution and activity of VEGFR-2 on glioma microvascular endothelial cell membranes treated with sorafenib and bradykinin suggested that the activity of VEGFR-2 could be regulated by its inhibitor or agonist.
\end{abstract}

Correspondence to: Dr Xiaofeng Lin, Department of Neurosurgery, Guangdong General Hospital, Guangdong Academy of Medical Sciences, 106 Zhongshan 2 Road, Yuexiu, Guangzhou, Guangdong 510080, P.R. China

E-mail: xflin9966@163.com

Key words: glioma, endothelial cell, vascular endothelial growth factor receptor-2, atomic force microscopy, sorafenib, bradykinin

\section{Introduction}

As one of the most common malignant tumors, glioma is difficult to excise completely or cure with surgery alone because of its high invasiveness and aggressive proliferative growth. Comprehensive approaches including surgery, chemotherapy, radiotherapy and biological therapy are internationally accepted treatments (1). However, the efficacy of the clinical treatment of malignant glioma remains unsatisfactory, affording a poor prognosis, and requires further exploration.

Malignant glioma is an intracranial malignant tumor with an extremely rich blood supply, which provides the nutritional support necessary for its proliferation, invasion and other biological behaviors (2). Therefore, it may be feasible to cut off the nutritional supply of glioma by inhibiting angiogenesis and consequently reducing the proliferative growth and invasive migration of tumor cells, thus treating the glioma (3). These theories have been widely recognized and hold great promise for a major breakthrough in glioma therapy in the near future by targeting angiogenesis (4).

Vascular endothelial growth factor (VEGF) is an important regulator of physiological angiogenesis and has been reported to be associated with pathological angiogenesis in tumors (5). In addition, VEGF and its receptor VEGFR-2, which exhibit high levels of expression in malignant glioma, have been reported to be closely associated with proliferation, invasion and angiogenesis in glioma (6). VEGFR-2 activates the synthesis of mitogen-activated protein (MAP) kinase and DNA via the phospholipase C-g/protein kinase C pathway (7). In addition, VEGFR-2 plays a direct signal conversion function in pathological angiogenesis (8). A previous study has demonstrated that the expression level of VEGFR-2 correlates positively with the degree of glioma malignancy (9). As a relevant signaling molecule, VEGFR-2 could function as a pivotal target for tumor therapy $(10,11)$.

Currently, several VEGF inhibitors, including axitinib, bevacizumab and pegaptanib, are undergoing clinical testing for a number of malignancies, such as lung cancer, gastric carcinoma, colon carcinoma and non-small cell lung cancer. The inhibition of VEGF is also being tested as a strategy to prevent angiogenesis (12). Therefore, VEGF and its receptor 
VEGFR-2 have become important targets in VEGF-targeted therapy for glioma $(3,4)$.

In human glioma tissues, VEGFR-2 is mainly distributed on the microvascular endothelial cell membrane surface of the glioma (13). In our previous study, an immune colloidal gold technique and atomic force microscopy (AFM) were used for the first time to indirectly localize and measure on a nanoscale level the number of VEGFR-2 molecules per unit area on the microvascular endothelial cell membrane surface of the glioma (13). The findings have provided a valuable foundation for research investigating anti-VEGFR-2 targeting therapy and VEGFR-2 blockade for the treatment of glioma. Given that the number of VEGFR-2 molecules on the surface membrane of one particular type of endothelial cell does not vary greatly, the effects of VEGFR-2 depend mostly on its activity, which is susceptible to intervention through the application of an inhibitor or agonist. In the present study, the possibility of regulating the activity of VEGFR-2 on the glioma microvascular endothelial cell membrane surface was investigated using the inhibitor sorafenib and agonist bradykinin.

\section{Materials and methods}

Experimental instruments. An atomic force microscope (SPM-9500J3; Shimadzu Corporation, Kyoto, Japan), cell incubator (SL-JC-2323; Bactron Sheldon Manufacturing Inc., Cornelius, OR, USA), and an inverted microscope (model IX 70; Olympus Corporation, Tokyo, Japan) were used in the present study.

Reagents and formulations. The following reagents were used: Rabbit anti-rat VEGFR-2 monoclonal antibody (BA0486; Wuhan Boster Bioengineering Co., Ltd.); M199 medium, fetal bovine serum, VEGF, double antibiotic solution (penicillin, streptomycin) (HyClone; GE Healthcare Life Sciences, Logan, UT, USA); bradykinin (Sigma-Aldrich; Merck Millipore, Darmstadt, Germany); acetone (Guangzhou Weijia Technology Co., Ltd., Guangzhou, China); sorafenib (Guangzhou Baiji Pharmacy, Guangzhou, China); and colloidal gold-labeled staphylococcal protein A (SPA-CG; CG diameter $15 \mathrm{~nm}$; Beijing Biosynthesis Biotechnology Co., Ltd., Beijing, China).

To prepare $1 \mathrm{mmol} / 1$ sorafenib, $6.37 \mathrm{mg}$ sorafenib was mixed with a small amount of dimethyl sulfoxide (DMSO), followed by the addition of ultrapure water to a constant volume of $10 \mathrm{ml}$ and stored at $-20^{\circ} \mathrm{C}$. To prepare $10 \mu \mathrm{mol} / 1$ bradykinin, $0.106 \mathrm{mg}$ bradykinin was mixed with ultrapure water to a constant volume of $10 \mathrm{ml}$ and stored at $-20^{\circ} \mathrm{C}$.

Cell culture. The glioma microvascular endothelial cell line (Cell Bank of the Shanghai Institute for Biological Sciences of the Chinese Academy of Sciences, Shanghai, China) was obtained from the primary cultivation of tumor tissue from a rodent brain tumor model. The cell line was further purified and identified based on the masculine expression of factor VIII-related antigen (fluorescent imaging showing the masculine expression of factor VIII-related antigen of the microvascular endothelial cell of the glioma as whole cells were uniformly dyed green) as previously described (13).

The cells were cultured in M199 medium containing $10 \%$ fetal bovine serum, $100 \mathrm{U} / \mathrm{ml}$ penicillin and $100 \mathrm{mg} / \mathrm{ml}$ streptomycin in an incubator $\left(5 \% \mathrm{CO}_{2}, 37^{\circ} \mathrm{C}\right)$ at a concentration of $1 \times 10^{5}$ cells $/ \mathrm{ml}$ for further measurements.

Experimental design and grouping. The cells were divided into three groups: i) A control group of untreated cells; ii) a sorafenib group consisting of cells treated with $1 \mathrm{mmol} / \mathrm{l}$ sorafenib; and iii) a bradykinin group of cells treated with $10 \mu \mathrm{mol} / \mathrm{l}$ bradykinin.

The cells in the sorafenib group were seeded on coverslips coated with $1 \%$ gelatin at a density of $1 \times 10^{5}$ cells $/ \mathrm{ml}$ in M199 culture medium. The cells were cultured in $5 \% \mathrm{CO}_{2}$ at $37^{\circ} \mathrm{C}$ for 2 days prior to replacement of the culture medium. Subsequently, $1 \mathrm{mmol} / \mathrm{l}$ sorafenib was added to a final concentration of $10 \mu \mathrm{mol} / 1$, and the cells were cultured for another 2 days (14).

The cells in the bradykinin group were seeded and cultured for 2 days, as described for the sorafenib group, prior to replacement of the culture medium. Subsequently, $10 \mu \mathrm{mol} / 1$ bradykinin was added to a final concentration of $0.1 \mu \mathrm{mol} / 1$, and the cells were cultured for another $18 \mathrm{~h}(15,16)$.

AFM imaging of SPA-CG and the IgG-SPA-CG complex Specimen preparation. A mixture of $1 \mu 1$ SPA-CG $(1.25 \mathrm{mg} / \mathrm{ml})$ and $0.01 \mathrm{M}$ PBS buffer at a ratio of 1:5,000 was prepared and vortexed thoroughly. A 5- $\mu \mathrm{l}$ aliquot of the liquid was pipetted onto a piece of mica and allowed to dry naturally. The surface was washed twice with deionized water to remove salt crystals and allowed to dry naturally. AFM was used to scan the specimen after $1 \mathrm{~min}$ at room temperature. For the second specimen, SPA-CG and VEGFR-2 monoclonal antibody (IgG) in PBS buffer at dilutions of 1:5 and 1:200, respectively, were combined to form a labeled IgG-SPA-CG complex by incubation at room temperature for $2 \mathrm{~h}$. The complex was then mixed with $0.01 \mathrm{M}$ PBS buffer at a ratio of 1:200. The liquid was applied to mica, as described for SPA-CG, and AFM was used to scan the specimen after $1 \mathrm{~min}$ at room temperature.

AFM parameters for scanning and imaging. The specimens were imaged in tapping mode with a cantilever elasticity of $2 \mathrm{n} / \mathrm{m}, 10 \mathrm{~nm}$ radius probe tip, 0.2-55 $\mu \mathrm{m}$ scanning range, $0.5-2 \mathrm{~Hz}$ scanning rate, 256x256 pixel display, and image acquisition in constant mode with an imaging force of $10^{-8} \mathrm{~N}$. Scanning was conducted in the presence of air. The scanning scope was continuously narrowed to gradually enlarge the scanned object. The SPA-CG and IgG-SPA-CG immune complexes on the mica sheet were imaged (17).

AFM imaging of the VEGFR-2 immune complex on glioma microvascular endothelial cell surfaces in the three groups Specimen preparation. Cells in the control, sorafenib and bradykinin groups were prepared using the methods described above. Approximately $1 \times 10^{5}$ cells $/ \mathrm{ml}$ were seeded onto gelatin-coated glass slides (final gelatin concentration, $1 \%$ ), grown until they were completely confluent and then rinsed three times with $0.01 \mathrm{M}$ PBS buffer. Subsequently, they were fixed with acetone at $-20^{\circ} \mathrm{C}$ for $5 \mathrm{~min}$. Rabbit anti-rat VEGFR-2 monoclonal antibody (1:200) was added to M199 medium, and the fixed cells were incubated with the antibody-containing medium in the refrigerator at $4^{\circ} \mathrm{C}$ overnight. The next day, 


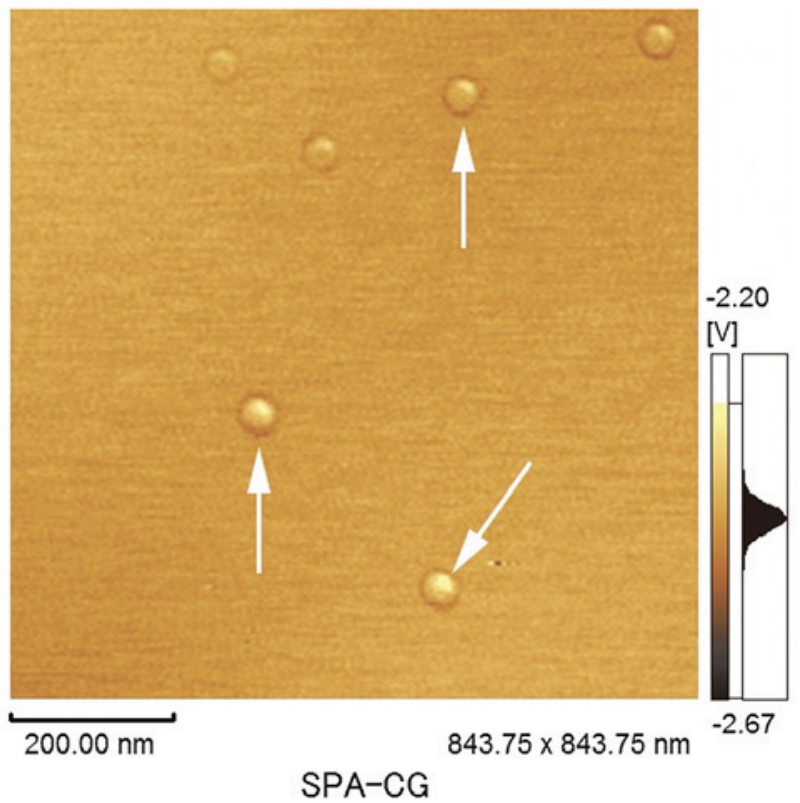

Figure 1. Atomic force microscopy imaging of SPA-CG on mica. Uniform globular structures of SPA-CG were observed on mica (indicated by arrows). SPA-CG, colloidal gold-labeled staphylococcal protein A.

the cells were rinsed three times for 10 min each with $0.1 \mathrm{M}$ PBS buffer. SPA-CG (1:5) was added to the medium during the last step, and the samples were incubated in the dark at room temperature for $2 \mathrm{~h}$ and then washed three times with $0.01 \mathrm{M}$ PBS buffer. The specimens were air-dried and scanned directly using AFM. In addition, cells incubated with SPA-CG and without IgG served as a blank control group. Endothelial cells in the blank control group were scanned by AFM imaging with or without SPA-CG to assess the binding of added SPA-CG to the cells.

AFM parameters for scanning and imaging. The AFM parameter settings were as described above (17). Imaging of IgG-SPA-CG immune complexes on the glioma microvascular endothelial cell surfaces in the three groups was performed as follows: Eight cells were selected randomly in each group, and two sections were randomly selected for scanning in each cell.

Statistical analysis. The density of VEGFR-2 on the glioma microvascular endothelial cell surface in each group was represented by the number of globular structures observed on the endothelial cell membrane surface within the designated unit area. Thus, the receptor density was represented by the number of globular structures per square micron (13). The receptor density of VEGFR-2 in each group was analyzed statistically and statistical analysis of differences was conducted using two independent sample t-tests with SPSS 13.0 software (SPSS, Inc., Chicago, IL, USA). $\mathrm{P}<0.05$ was considered to indicate a statistically significant difference.

\section{Results}

In the present study, in order to investigate changes in the activity of VEGFR-2 on glioma microvascular endothelial

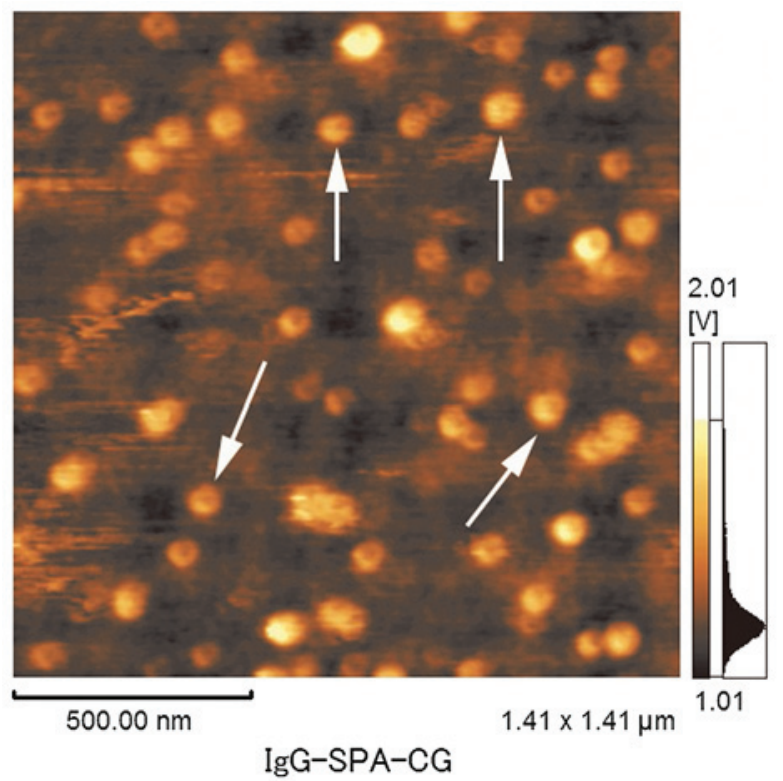

Figure 2. Atomic force microscopy imaging of IgG-SPA-CG on mica. Uniform globular structures of IgG-SPA-CG immune complexes were observed on mica (indicated by arrows). IgG-SPA-CG, colloidal gold-labeled staphylococcal protein A complexed with vascular endothelial growth factor receptor 2 monoclonal antibody.

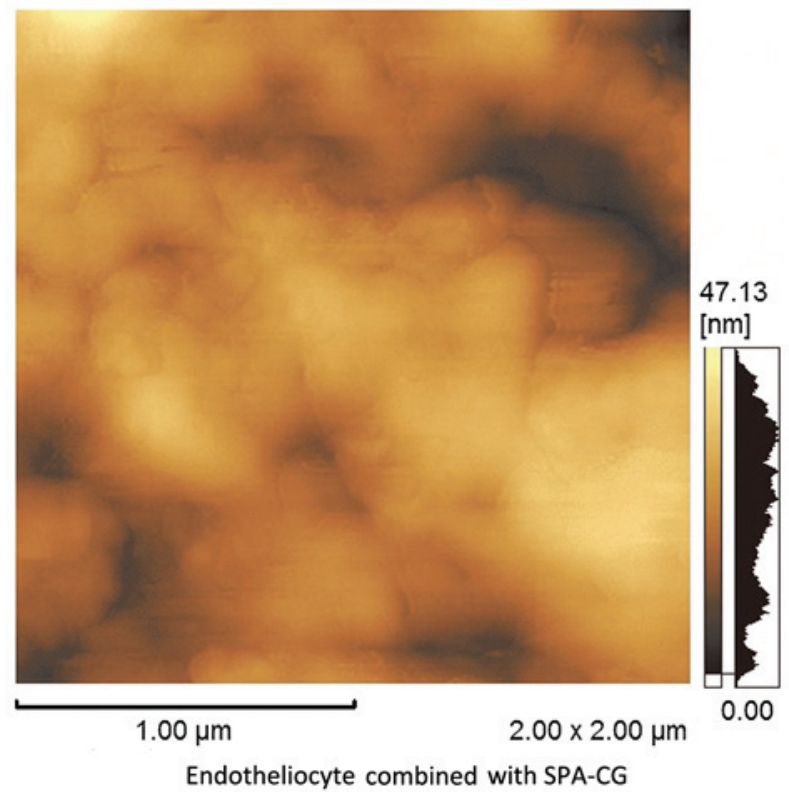

Figure 3. Atomic force microscopy imaging of the glioma microvascular endothelial cell surface with SPA-CG. No globular structures were observed on the endothelial cell surface. SPA-CG, colloidal gold-labeled staphylococcal protein $\mathrm{A}$.

cell membranes, cells were treated with the VEGFR-2 inhibitor sorafenib or agonist bradykinin and analyzed by AFM imaging of VEGFR-2 immune complexes bound to the cell surfaces.

AFM imaging of SPA-CG and IgG-SPA-CG on mica. On mica, SPA-CG and IgG-SPA-CG complexes appeared as uniform, globular structures (Figs. 1 and 2). No globular structures were observed on the surfaces of the blank control glioma 


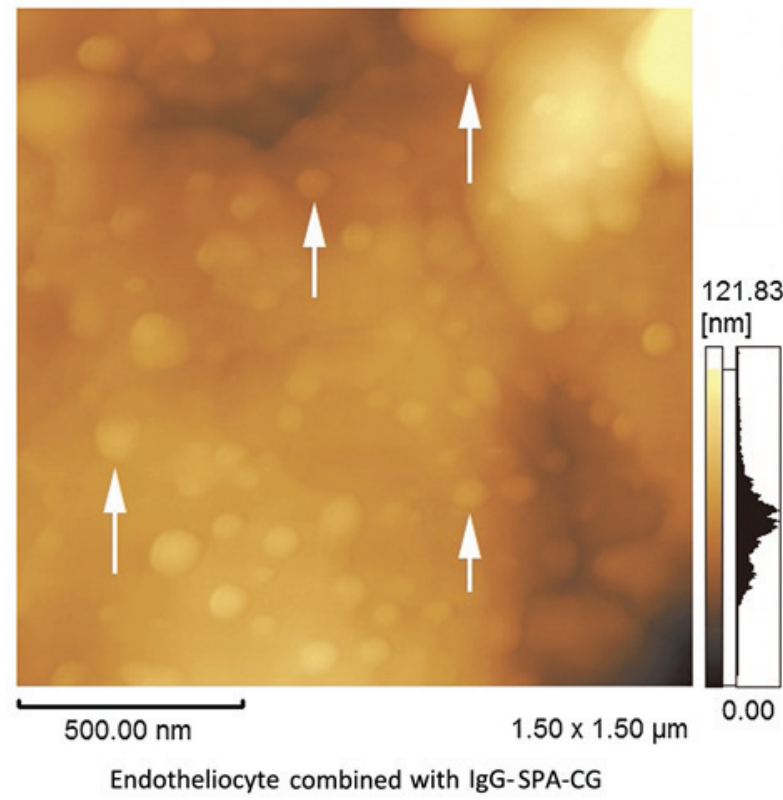

Figure 4. Atomic force microscopy imaging of the distribution of VEGFR-2 immune complexes on the glioma microvascular endothelial cell surface in the control group. Numerous globular structures were evenly distributed on the endothelial cell surface (indicated by arrows). VEGFR-2, vascular endothelial growth factor receptor 2; IgG-SPA-CG, colloidal gold-labeled staphylococcal protein A complexed with VEGFR-2 monoclonal antibody.

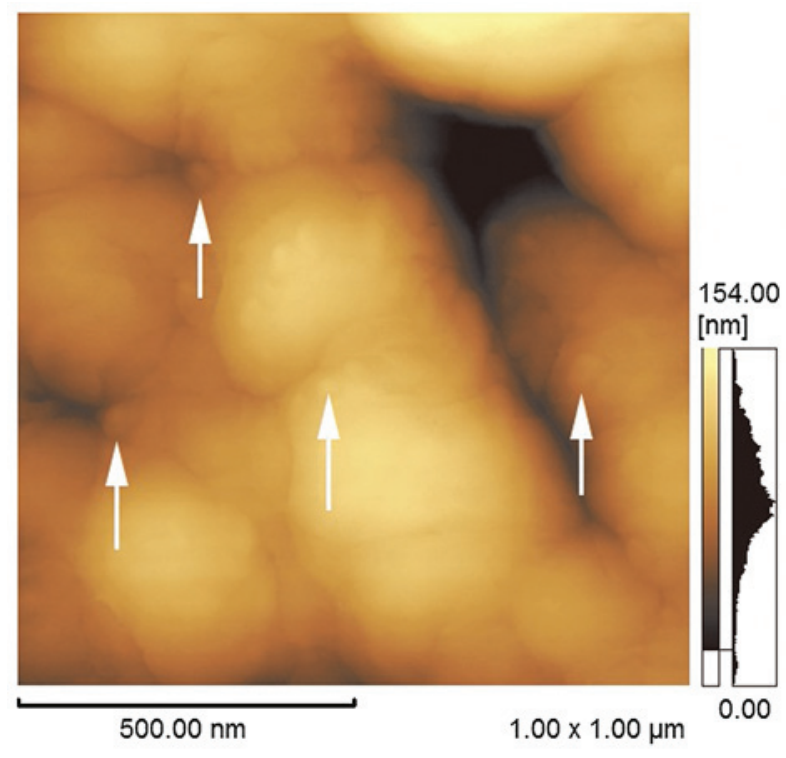

Sorafenib-treated endotheliocyte combined with IgG-SPA-CG

Figure 5. Atomic force microscopy imaging of the distribution of VEGFR-2 immune complexes on the glioma microvascular endothelial cell surface in the sorafenib group. Only a few globular structures were scattered on the endothelial cell surface (indicated by arrows). VEGFR-2, vascular endothelial growth factor receptor 2; IgG-SPA-CG, colloidal gold-labeled staphylococcal protein A complexed with VEGFR-2 monoclonal antibody.

microvascular endothelial cells treated with SPA-CG without the addition of anti-VEGF-2 antibody (Fig. 3). Numerous evenly distributed globular structures were observed on the surfaces of the glioma microvascular endothelial cells in the control group (Fig. 4), exhibiting a density of $\sim 92 \pm 21 / \mu \mathrm{m}^{2}$, consistent with our previous study (11).

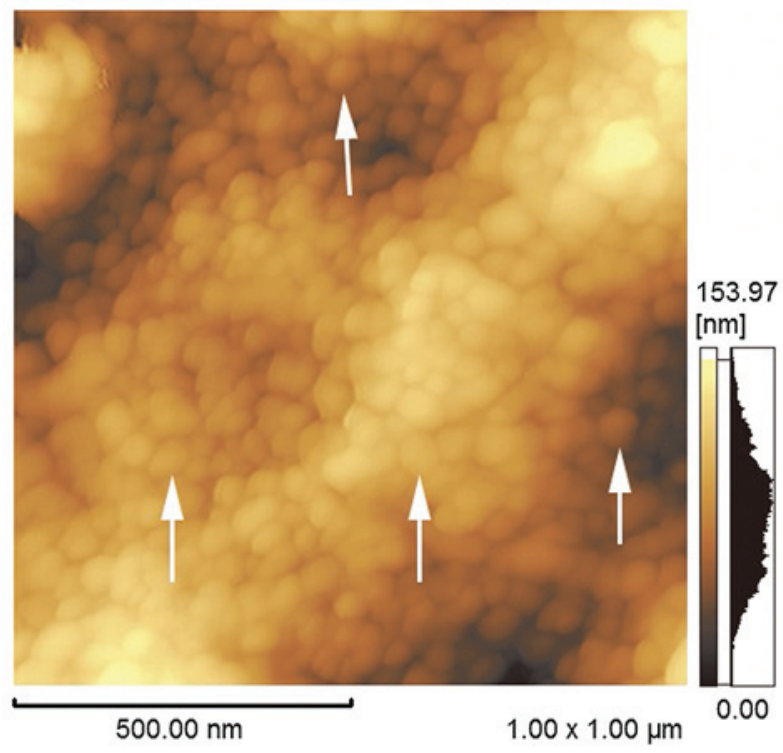

Bradykinin -treated endotheliocyte combined with IgG-SPA-CG

Figure 6. Atomic force microscopy imaging of the distribution of VEGFR-2 immune complexes on the glioma microvascular endothelial cell surface in the bradykinin group. Numerous globular structures were densely distributed on the endothelial cell surface (indicated by arrows). VEGFR-2, vascular endothelial growth factor receptor 2; IgG-SPA-CG, colloidal gold-labeled staphylococcal protein A complexed with VEGFR-2 monoclonal antibody.

AFM imaging of endotheliocytes treated with sorafenib. Only a few, scattered globular structures were observed on the surfaces of glioma microvascular endothelial cells in the sorafenib group (Fig. 5), demonstrating a density of $\sim 18 \pm 7 / \mu \mathrm{m}^{2}$, which was significantly lower than that calculated for the control group $(\mathrm{P}<0.01)$.

AFM imaging of endotheliocytes treated with bradykinin. A large number of densely globular structures were observed on the surfaces of the glioma microvascular endothelial cells in the bradykinin group (Fig. 6), with a density of $\sim 199 \pm 23 / \mu \mathrm{m}^{2}$, which was significantly higher than that determined for the control group $(\mathrm{P}<0.01)$.

\section{Discussion}

With the exploration of biological therapy for the treatment of malignant glioma, particularly anti-angiogenic therapy, bevacizumab, a therapeutic agent that targets angiogenesis, has demonstrated positive effects in phase III trials for the treatment of primary and recurrent glioma (18). Among the three types of specific VEGF receptors, VEGFR-2 is associated with vascular endothelial cell proliferation and angiogenesis. VEGF binding to VEGFR-2 stimulates division and proliferation in endothelial cells, induces neovascularization, and increases vascular permeability. Therefore, VEGF and its receptor VEGFR-2 play important roles in tumor angiogenesis (19). Overexpression of VEGFR-2 participates in proliferation, invasion and tumor angiogenesis in glioma, and its expression levels have been positively correlated with the proliferation, invasion, angiogenesis and degree of malignancy in this condition $(20,21)$. Therefore, many researchers have attempted to establish an effective anti-angiogenic therapy by targeting VEGFR-2 $(22,23)$. 
Sorafenib is a multiple kinase inhibitor that is able to inhibit a variety of kinases within or on cell surfaces, including RAF kinase, VEGFR-2, VEGFR-3, platelet-derived growth factor receptor- $\beta$ (PDGFR- $\beta$ ), KIT and fms-related tyrosine kinase 3 FLT-3 (24). Sorafenib can block tumor angiogenesis by inhibiting VEGFR and PDGFR, and indirectly inhibits the growth of tumor cells $(14,25-27)$. Thus, sorafenib may be a targeted inhibitor of VEGFR-2. Bradykinin induces the secretion of nitric oxide synthase and promotes nitric oxide (NO) synthesis in endothelial cells that are involved in the angiogenesis-promoting effects of VEGF, and it has been positively correlated with the expression of VEGF (28). In addition, VEGF promotes NO receptor expression. As a potent agonist of VEGFR-2, bradykinin promotes the expression of VEGFR-2 and its binding to VEGF.

AFM combined with colloidal gold immune complexes was shown to identify, localize and measure the density of VEGFR-2 on the surfaces of endothelial cells in our previous study, revealing a VEGFR-2 density of $\sim 92 / \mu \mathrm{m}^{2}$ (13). This finding provides direct information regarding the distribution of VEGFR-2 on microvascular endothelial cell membranes in glioma at the cellular level. In the current study, the above precondition was used as a control to explore the possibility of regulating the activity of VEGFR-2 on glioma microvascular endothelial cell membranes on a nanoscale and to investigate the effects of the VEGFR-2 inhibitor sorafenib and agonist bradykinin on the activity of VEGFR-2. The aim was to investigate the effect of the inhibitor or agonist on the distribution and receptor density of VEGFR-2 on a nanoscale and to indirectly evaluate the possibility of regulating VEGFR-2 with its inhibitor or agonist. The results demonstrated that no globular complex structures were present on the surfaces of the endothelial cells in the blank control with or without the addition of SPA-CG, which indicated that no globular complexes formed with VEGFR-2 in the absence of VEGFR-2 monoclonal antibody regardless of the addition of SAP-CG. In the control group, numerous globular structures were evenly distributed on the endothelial cell surface, and the majority of the VEGFR-2 molecules were active.

In the sorafenib group, only a few scattered globular complexes were observed on the endothelial cell membrane surfaces, demonstrating a density of only $18 / \mu \mathrm{m}^{2}$, which was significantly lower than that determined for the control group $\left(92 / \mu \mathrm{m}^{2}\right)$. This finding indicated that the function of VEGFR-2 was inhibited by sorafenib and that only a few VEGFR-2 molecules were active. The present results demonstrate the inhibitory effect of sorafenib on VEGFR-2 on glioma microvascular endothelial cell membranes and provide a basis for the use of sorafenib in anti-angiogenic therapy targeting glioma.

Numerous globular structures were densely distributed on the endothelial cell membrane surfaces in the bradykinin group, exhibiting a density of $\leq 199 / \mu \mathrm{m}^{2}$, which was significantly higher than that quantified for the control group $\left(92 / \mu \mathrm{m}^{2}\right)$. This finding indicated that, although the majority of the VEGFR-2 molecules on the glioma microvascular endothelial cell membrane surfaces were active, a considerable number of receptors were inactive and so could be activated by the agonist bradykinin, resulting in an increase in activated VEGFR-2.
The current study demonstrated that both the VEGFR-2 inhibitor and agonist regulated the activity of VEGFR-2. The observation that VEGFR-2 inhibitors can inactivate VEGFR-2 suggests that such inhibitors may have a suppressive effect on angiogenesis in glioma, indicating that VEGFR-2 may be an important potential therapeutic target in anti-angiogenic treatments for this condition.

Tumor angiogenesis is a crucial process in the generation, development and metastasis of solid tumors. Since tumor angiogenesis is closely associated with the biological behavior of glioma, including abnormal growth, proliferation and invasion, anti-angiogenic therapy has broad applications for the treatment of this disease (29). The findings of the current study provide a concrete foundation for the further development of anti-VEGFR-2-targeting therapies for glioma.

\section{Acknowledgements}

This study was supported by Science and Technology Planning Project of Guangdong Province (grant no. 2012B031800165) and National Natural Science Foundation of China (grant no. 81201995).

\section{References}

1. Levy S, Chapet S and Mazeron JJ: Management of gliomas. Cancer Radiother 18: 461-467, 2014 (In French).

2. Visted T, Enger PO, Lund-Johansen M and Bjerkvig R: Mechanisms of tumor cell invasion and angiogenesis in the central nervous system. Front Biosci 8: e289-e304, 2003.

3. Chamberlain MC and Raizer J: Antiangiogenic therapy for high-grade gliomas. Cns Neurol Disord Drug Targets 8: 184-194, 2009.

4. Argyriou AA, Giannopoulou E and Kalofonos HP: Angiogenesis and anti-angiogenic molecularly targeted therapies in malignant gliomas. Oncology 77: 1-11, 2009.

5. Ferrara N, Gerber HP and LeCouter J: The biology of VEGF and its receptors. Nat Med 9: 669-676, 2003.

6. Puputti M, Tynninen O, Sihto H, Blom T, Mäenpää H, Isola J, Paetau A, Joensuu H and Nupponen NN: Amplification of KIT, PDGFRA, VEGFR2, and EGFR in gliomas. Mol Cancer Res 4: 927-934, 2006

7. Takahashi T, Ueno $H$ and Shibuya M: VEGF activates protein kinase C-dependent, but Ras-independent Raf-MEK-MAP kinase pathway for DNA synthesis in primary endothelial cells. Oncogene 18: 2221-2230, 1999.

8. Cui H, Wang Y, Huang H, Yu W, Bai M, Zhang L, Bryan BA, Wang Y, Luo J, Li D, et al: GPR126 protein regulates developmental and pathological angiogenesis through modulation of VEGFR2 receptor signaling. J Biol Chem 289: 34871-34885, 2014.

9. Cai W, Chen K, Mohamedali KA, Cao Q, Gambhir SS Rosenblum MG and Chen X: PET of vascular endothelial growth factor receptor expression. J Nucl Med 47: 2048-2056, 2006.

10. Shibuya M: Differential roles of vascular endothelial growth factor receptor-1 and receptor-2 in angiogenesis. J Biochem Mol Biol 39: 469-478, 2006.

11. Li JT, Yan Q and Yu HL: Expression of VEGF and NGF in gliomas of human. Sichuan Da Xue Xue Bao Yi Xue Ban 40: 408-411, 2009 (In Chinese).

12. Ellis LM and Hicklin DJ: VEGF-targeted therapy: Mechanisms of anti-tumour activity. Nat Rev Cancer 8: 579-591, 2008.

13. Zhou D, Zhan S, Zhou D, Li Z, Lin X, Tang K, Shu H, Chen G, Zeng S, Cai Y and Jiang X: A study of the distribution and density of the VEGFR-2 receptor on glioma microvascular endothelial cell membranes. Cell Mol Neurobiol 31: 687-694, 2011.

14. Jane EP, Premkumar DR and Pollack IF: Coadministration of sorafenib with rottlerin potently inhibits cell proliferation and migration in human malignant glioma cells. J Pharmacol Exp Ther 319: 1070-1080, 2006. 
15. Zhou L, Yang B, Wang Y, Zhang HL, Chen RW and Wang YB: Bradykinin regulates the expression of claudin-5 in brain microvascular endothelial cells via calcium-induced calcium release. J Neurosci Res 92: 597-606, 2014.

16. Wang YB, Peng C and Liu YH: Low dose of bradykinin selectively increases intracellular calcium in glioma cells. J Neurol Sci 258: 44-51, 2007.

17. Zhou D, Jiang X, Xu R, Cai Y, Hu J, Xu G, Zou Y and Zeng Y: Assessing the cytoskeletal system and its elements in C6 glioma cells and astrocytes by atomic force microscopy. Cell Mol Neurobiol 28: 895-905, 2008.

18. Chinot OL and Reardon DA: The future of antiangiogenic treatment in glioblastoma. Curr Opin Neurol 27: 675-682, 2014

19. Sharma PS, Sharma R and Tyagi T: VEGF/VEGFR pathway inhibitors as anti-angiogenic agents: Present and future. Curr Cancer Drug Targets 11: 624-653, 2011.

20. Yao X, Ping Y, Liu Y, Chen K, Yoshimura T, Liu M, Gong W, Chen C, Niu Q, Guo D, et al: Vascular endothelial growth factor receptor 2 (VEGFR-2) plays a key role in vasculogenic mimicry formation, neovascularization and tumor initiation by Glioma stem-like cells. PLoS One 8: e57188, 2013.

21. Kuczynski EA,Patten SG and Coomber BL: VEGFR2 Expression and TGF- $\beta$ signaling in initial and recurrent high-grade human glioma. Oncology 81: 126-134, 2011.

22. Hamerlik P, Lathia JD, Rasmussen R, Wu Q, Bartkova J, Lee M, Moudry P, Bartek J Jr, Fischer W, Lukas J, et al: Autocrine VEGF-VEGFR2-Neuropilin-1 signaling promotes glioma stem-like cell viability and tumor growth. J Exp Med 209: 507-520, 2012
23. Yakes FM, Chen J, Tan J, Yamaguchi K, Shi Y, Yu P, Qian F, Chu F, Bentzien F, Cancilla B, et al: Cabozantinib (XL184), a Novel MET and VEGFR2 inhibitor, simultaneously suppresses metastasis, angiogenesis, and tumor growth. Mol Cancer Ther 10: 2298-2308, 2011.

24. Wilhelm SM, Adnane L, Newell P, Villanueva A, Llovet JM and Lynch M: Preclinical overview of sorafenib, a multikinase inhibitor that targets both Raf and VEGF and PDGF receptor tyrosine kinase signaling. Mol Cancer Ther 7: 3129-3140, 2008.

25. Arora A and Scholar EM: Role of tyrosine kinase inhibitors in cancer therapy. J Pharmacol Exp Ther 315: 971-979, 2005.

26. Adnane L, Trail PA, Taylor I and Wilhelm SM: Sorafenib (BAY 43-9006, Nexavar), a dual-action inhibitor that targets RAF/MEK/ERK pathway in tumor cells and tyrosine kinases VEGFR/PDGFR in tumor vasculature. Methods Enzymol 407: 597-612, 2006

27. Rini BI: Sorafenib. Expert Opin Pharmacother 7: 453-461, 2006.

28. Moraes MS, Costa PE, Batista WL, Paschoalin T, Curcio MF, Borges RE, Taha MO, Fonseca FV, Stern A and Monteiro HP: Endothelium-derived nitric oxide (NO) activates the NO-epidermal growth factor receptor-mediated signaling pathway in bradykinin-stimulated angiogenesis. Arch Biochem Biophys 558: 14-27, 2014

29. Batchelor TT, Reardon DA, de Groot JF, Wick W and Weller M: Antiangiogenic therapy for glioblastoma: Current status and future prospects. Clin Cancer Res 20: 5612-5619, 2014. 